\title{
Kinetic Study of the Thermochemical Degradation of Lignocellulosic Materials Based on TG-FTIR, Py-GC/MS and ${ }^{13} \mathrm{C}$ NMR Experiments
}

\author{
I. Hrablay and L. Jelemenský" \\ Department of Chemical and Biochemical Engineering, \\ Institute of Chemical and Environmental Engineering, \\ Faculty of Chemical and Food Technology, \\ Slovak University of Technology, Radlinského 9, \\ 812 37, Bratislava, Slovakia
}

doi: 10.15255/CABEQ.2015.2309

Original scientific paper

Received: October 1, 2015

Accepted: September 2, 2016

\begin{abstract}
Pyrolysis of a hardwood representative, beech sawdust (Fagus sylvatica), was investigated by thermogravimetry, a thermal analysis technique. A suitable kinetic approach for the determination of kinetic parameters was proposed. The model fitting method was used to optimize the kinetic parameters of the reaction pathways of the selected reaction mechanisms. The experiments were conducted starting from ambient temperature up to $600{ }^{\circ} \mathrm{C}$ using the following five heating rates: $2,5,10,15$, and $20^{\circ} \mathrm{C} \mathrm{min}{ }^{-1}$. FTIR, Py$\mathrm{GC} / \mathrm{MS},{ }^{13} \mathrm{C}$ NMR, and elemental analysis were also used to analyse the pyrolysis products. Differentiation among the reaction mechanisms of lignocellulosic material pyrolysis was performed. The three-step parallel mechanism containing an intermediate was the most suitable mechanism based on ${ }^{13} \mathrm{C}$ NMR analysis of solid residues prepared at the selected temperatures from $230-500{ }^{\circ} \mathrm{C}$. The NMR results showed that the inclusion of an intermediate into the reaction scheme was a reasonable step. It was concluded that the intermediate was connected with the lignin structure.
\end{abstract}

Key words:

kinetics, wood pyrolysis, mechanism, TG-FTIR, NMR, Py-GC/MS

\section{Introduction}

In the long history of solid-state kinetic theory, pyrolysis of cellulose ${ }^{1-5}$, hemicellulose $\mathrm{e}^{6-8}$, and lig$\operatorname{nin}^{8-10}$, as the key representative lignocellulosic materials, have been thoroughly studied. Although pyrolysis reaction dynamics and reaction schemes for the whole lignocellulosic substrate have evolved substantially, many questions concerning the pyrolysis mechanism remain, due to the high complexity of the reactions and the many variations in the physical and chemical properties of biomass ${ }^{11}$. Conventional thermogravimetric (TG) analysis does not clearly demonstrate the most appropriate mechanism. Additional analytical techniques for the analysis of pyrolysis products and intermediates, as well as structural changes in the material have to be used $^{12}$. One of the most frequently used techniques is evolved gas analysis (EGA), but a variety of analytical techniques are used, such as Fourier transform infrared spectroscopy (FTIR), high-performance liquid chromatography (HPLC), gas chromatography (GC), mass spectrometry (MS), or their combination (GC/MS). To identify structural changes of solid materials, scanning electron mi-

${ }^{*}$ Corresponding author. Tel.: +421(0)259325 250.

E-mail address: ludovit.jelemensky@stuba.sk croscopy (SEM) and nuclear magnetic resonance (NMR) are often used. ${ }^{13} \mathrm{C}$ NMR has been often used and cited in the literature as a promising method that provides important results regarding biomass transformation into char ${ }^{13-16}$. Based on analytical results, many authors have reported either speculative reaction mechanisms including exact chemical reactions, or simplified forms of reaction mechanisms including reaction pathways. Some efforts to better understand the chemical pathways were made using much simpler model compounds, such as glucose, levoglucosan, glycerin, and glyceraldehydes ${ }^{17-20}$. Wang et al. ${ }^{21}$ also adopted microcrystalline cellulose as a model compound. These compounds are formed as intermediates or products during cellulose pyrolysis. However, although the approach of using simplified model compounds is widespread, these model compounds form only a small percentage of the whole palette of pyrolysis products, and their interactions cannot be neglected.

The literature presents various decomposition mechanisms applicable to biomass pyrolysis. An initial mechanism of cellulose pyrolysis, the twostep competitive mechanism, describing cellulose transformation into volatiles in the first step and into char with gases in the second step, was presented by Kilzer F. J. and Broid A. ${ }^{1}$ and later by Broido A. and Nelson M. A. ${ }^{22}$ (Fig. 1). 


$$
\text { Cellulose } \underset{k_{2}}{\stackrel{k_{1}}{\longrightarrow} \text { Tar }} \text { Char + Gas }
$$

Fig. 1 - Incipient mechanism of cellulose pyrolysis proposed by Broido's group $(1965)^{l}\left(k_{1}\right.$ and $k_{2}$ are rate constants of the respective reaction pathway)

Thus, specific types of both reaction pathways were identified ${ }^{23-25}$, transglycosylation produces volatile tars, and elimination produces light gases and char with activation energies of $190-200 \mathrm{~kJ} \mathrm{~mol}^{-1}$ and $250 \mathrm{~kJ} \mathrm{~mol}^{-1}$, respectively ${ }^{26}$. The hypothesis of two competing reaction steps has been continuously modified and clarified. The most important contribution was including the so-called "active cellulose" or "intermediate" into the reaction scheme $\mathrm{e}^{2,4,5,27}$ (Fig. 2).

$$
\text { Cellulose } \stackrel{k_{1}}{\longrightarrow} \text { (Active cellulose) } \underset{k_{3}}{\stackrel{k_{2}}{\longrightarrow}} \operatorname{Tar} \text { Char + Gas }
$$

Fig. 2 - Mechanism of cellulose pyrolysis with a reaction intermediate, "active cellulose", proposed by Bradburry (1979)2 $\left(k_{1}, k_{2}\right.$, and $k_{3}$ are rate constants of the respective reaction pathway)

This intermediate is thought to be produced in an initial reaction step that is not associated with any mass loss while the degree of polymerization decreases. The kinetic parameters of cellulose transformation to its active form, according to the scheme presented in Fig. 2, are reported by Bradburry et $a .^{2}$; the activation energy and pre-exponential factor were $242 \mathrm{~kJ} \mathrm{~mol}^{-1}$ and $2.8 \cdot 10^{19} \mathrm{~s}^{-1}$, respectively. However, there is still no consensus on the existence of this intermediate in literature. The transformation of cellulose to active cellulose is reported as either very fast or not present at all ${ }^{3,28}$. In the three-step mechanism assuming biomass decomposition via three parallel reactions, the intermediate is simply omitted ${ }^{29,30}$, which can be considered an adequate overall representation, but it is not correct on the molecular level ${ }^{31}$. An improved mechanism of formation and consequent evaluation of active cellulose during cellulose pyrolysis was proposed by Liu et al. ${ }^{32}$

The aim of this paper was to identify a suitable kinetic model by differentiating the reaction mechanisms of lignocellulosic materials thermal decomposition based on experimental results. TG experimental data were compared with those obtained by mathematical models of different reaction mechanisms employing optimization procedures. The results show that the differentiation between the proposed reaction mechanisms based strictly only on TG experiments is not sufficient because the calculated values of objective functions for different re- action mechanisms are similar. The present study shows that, through the combination of TG data with experimental data from FTIR, Py-GC/MS and NMR reflecting the compositional and structural changes of the decomposed material and evolved products, should provide valuable assistance in the selection of a suitable reaction mechanism.

\section{Materials and methods}

\section{TG and elemental analysis}

Experiments were conducted in a simultaneous thermogravimetric analyser STA 409 PC Luxx ${ }^{\circledR}$ (Netzsch-Gerätebau GmbH, Selb, Germany). The reaction environment was purged with argon flow of $60 \mathrm{~mL} \mathrm{~min}{ }^{-1}$. The mass of the sample was approximately $20 \mathrm{mg}$ of the hardwood beech sawdust (Fagus sylvatica). Samples in powder form were prepared by milling in a ball mill and sifting through a $0.5 \mathrm{~mm}$ sieve. The experiments were conducted starting from ambient temperature up to $600{ }^{\circ} \mathrm{C}$ using the following five heating rates: $2,5,10,15$, and $20{ }^{\circ} \mathrm{C} \mathrm{min}^{-1}$.

Solid residue samples for NMR analysis were prepared by a TG analyser. The experiments were conducted starting from ambient temperature up to the temperatures listed in Table 1. The temperature program consisted of a dynamic sequence with a heating rate of $5{ }^{\circ} \mathrm{C} \mathrm{min}^{-1}$ and an isothermal sequence of $20 \mathrm{~min}$. Temperatures for sample preparation were selected in regard to the solid residue, characterizing structural changes in the wooden matter during pyrolysis. Table 1 also includes the mass fractions of $\mathrm{C}$ and $\mathrm{H}$, and the $\mathrm{C} / \mathrm{H}$ ratio from the elemental analysis of solid residues used for the NMR analysis. Weight loss is presented in the form of mean values computed from at least two repeated runs, and the mass fractions of $\mathrm{C}$ and $\mathrm{H}$ are the mean values with the absolute deviations in parentheses computed from repeated analyses. Elemental analysis was performed using a vario MACRO cube (Elementar Analysensysteme GmbH, Hanau, Germany).

\section{NMR analysis}

Solid residues were analysed using a Varian VNMRS $600 \mathrm{MHz}$ (Oxford Instruments, Ltd.) with a superconducting magnet of $14.1 \mathrm{~T}$ induction, and a $3.2 \mathrm{~mm}$ probe (Narrow Bore Triple Resonance HXY MAS). Samples were placed in thick-wall rotors with a rotation of $18000 \mathrm{~Hz}$. The correct spectral scale was achieved using the $\mathrm{CH}_{2}$ group of adamantine as the reference. The impulse sequence consisted of a $5 \mathrm{~s}$ relaxation, spin echo, and $19.3 \mathrm{~ms}$ acquisition. The chemical shifts of cellulose, hemi- 


\begin{tabular}{|c|c|c|c|c|}
\hline \multirow{2}{*}{$\begin{array}{c}\text { Final } \\
\text { temperature } \\
{\left[{ }^{\circ} \mathrm{C}\right]}\end{array}$} & \multirow{2}{*}{$\begin{array}{c}\text { Weight loss } \\
{[\%]}\end{array}$} & \multicolumn{3}{|c|}{$\begin{array}{c}\text { Mass fractions of } \mathrm{C} \text { and } \mathrm{H} \\
{[\text { mass } \%]}\end{array}$} \\
\hline & & $\mathrm{C}$ & $\mathrm{H}$ & $\mathrm{C} / \mathrm{H}$ \\
\hline raw sample & - & $46.2(0.11)$ & $6.3(0.05)$ & 7.3 \\
\hline 230 & 10.7 & $47.9(0.04)$ & $6.1(0.08)$ & 7.9 \\
\hline 250 & 19.6 & $50.1(0.08)$ & $6.0(0.04)$ & 8.4 \\
\hline 270 & 28.4 & $50.7(0.07)$ & $5.9(0.01)$ & 8.6 \\
\hline 290 & 39.9 & $54.7(0.18)$ & $5.7(0.02)$ & 9.6 \\
\hline 300 & 45.1 & - & - & - \\
\hline 310 & 54.9 & $61.0(0.05)$ & $5.2(0.02)$ & 11.7 \\
\hline 320 & 62.3 & - & - & - \\
\hline 330 & 65.5 & $69.2(0.10)$ & $4.5(0.03)$ & 15.4 \\
\hline 340 & 67.2 & - & - & - \\
\hline 350 & 70.4 & $70.9(0.27)$ & $4.1(0.07)$ & 17.3 \\
\hline 410 & 74.6 & $72.8(0.13)$ & $3.3(0.09)$ & 22.1 \\
\hline 500 & 76.6 & $74.3(0.11)$ & $3.1(0.06)$ & 24.0 \\
\hline
\end{tabular}

Table 2 - Chemical shifts of carbon identified in the spectra of solid residues prepared at the temperatures from Table 1

\begin{tabular}{|c|c|c|}
\hline $\begin{array}{l}\text { Chemical shift } \\
{[\mathrm{ppm}]}\end{array}$ & Carbon specification & Labelling \\
\hline 21 & hemicellulose $\mathrm{CH}_{3}-\mathrm{COO}-$ & H1 \\
\hline 56 & lignin $\mathrm{OCH}_{3}$ & L1 \\
\hline 62 & cellulose C-6 (amorphous) & $\mathrm{C} 1$ \\
\hline 65 & cellulose C-6 (crystalline) & $\mathrm{C} 2$ \\
\hline 72 & cellulose $\mathrm{C}-2 / 3 / 5$ & $\mathrm{C} 3$ \\
\hline 75 & cellulose $\mathrm{C}-2 / 3 / 5$ & $\mathrm{C} 4$ \\
\hline 84 & cellulose C-4 (amorphous) & $\mathrm{C} 5$ \\
\hline 89 & cellulose C-4 (crystalline) & C6 \\
\hline 105 & cellulose $\mathrm{C}-1$ & $\mathrm{C} 7$ \\
\hline 121 & lignin G-6 & L2 \\
\hline $133-134$ & $\begin{array}{l}\text { lignin S-1 (ne), S-4 (ne) } \\
\text { lignin G-1 (ne) }\end{array}$ & L3 \\
\hline $138-139$ & $\begin{array}{l}\text { lignin S-1 (e), S-4 (e) } \\
\text { lignin G-1 (e) }\end{array}$ & L4 \\
\hline $147-148$ & $\begin{array}{l}\text { lignin S-3 (ne), S-5 (ne) } \\
\text { lignin G-3 (ne, e), G-4 (ne, e) }\end{array}$ & L5 \\
\hline 153 & lignin S-3 (e), S-5 (e) & L6 \\
\hline 172 & $\begin{array}{l}\text { hemicellulose }-\mathrm{COO}-\mathrm{R} \\
\text { hemicellulose } \mathrm{CH}_{3}-\mathrm{COO}-\end{array}$ & $\mathrm{H} 2$ \\
\hline
\end{tabular}

$\mathrm{S}$ : carbon in syringyls, G: carbon in guaiacyls, ne: in nonetherified arylglycerol $\beta$-aryl ethers, e: in etherified arylglycerol $\beta$-aryl ethers

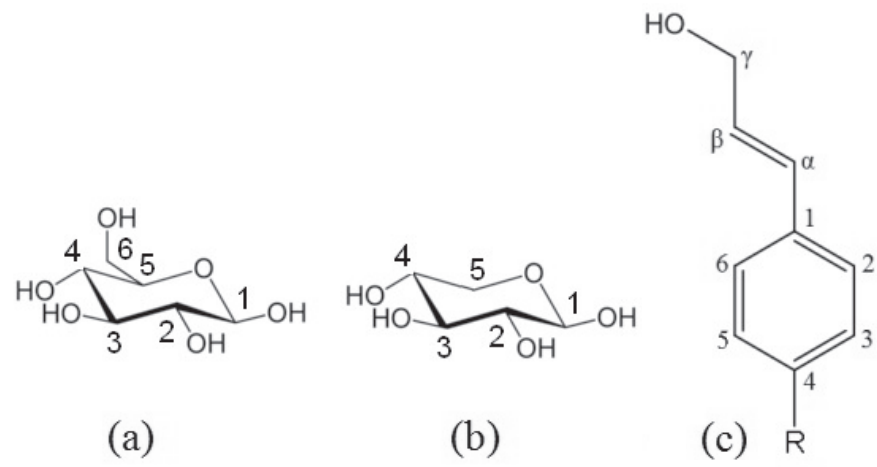

Fig. 3 - Carbon position labelling in the main wood components: (a) cellulose, (b) hemicellulose ( $\beta$-D-xylopyranose unit, acetyl groups are not shown), c) lignin monomer (guaiacyl methoxyl group at position 3, syringyl - methoxyl groups at position 3 and 5 )

cellulose, and lignin groups were assigned according to Table 2 based on literature ${ }^{33-35}$. The position of carbon was labelled according to Fig. 3.

\section{FTIR analysis}

Experiments were carried out using a combination of the thermal analyser already described in previous chapter and an infrared type TENSOR 27 spectrometer with Fourier transformation (Bruker Optik GmbH in Ettlingen, Germany). This connection allows online recording of the spectrum of released volatiles. The two systems were connected using a heated transfer line to avoid condensation of released volatiles. Each measurement was performed at a heating rate of $20{ }^{\circ} \mathrm{C} \mathrm{min}-1$ to achieve the best response of the released volatiles in the interferogram. Compounds were identified using various online libraries accessible free of charge. According to the Lambert-Beer law, the absorbance measured is linearly dependent on the gas concentration $^{36}$. Thus, the variation of individual compounds' absorbance represents changes in their concentration. Identification of individual compounds in the complex spectrum of the wood biomass pyrolysis products is not a simple task, as it is, at best, possible to identify individual gases, although only the functional groups of all compounds can usually be identified. The most critical problem for identification is the overlapping of individual peaks in the spectra, although it is possible to identify the most important functional groups and individual compounds.

\section{Py-GC/MS analysis}

To provide more precise and complementary information about the gaseous composition, $\mathrm{Py}-\mathrm{GC} /$ MS analysis was used. Fast pyrolysis experiments were performed with a Pyroprobe 5000 Series (CDS Analytical Inc., Oxford, USA) using a GC 7890A 
gas chromatograph (Agilent Technologies, Inc. Wilmington, USA). The pyrolyzer was interfaced (interface temperature of $50^{\circ} \mathrm{C}$ ), and approximately $3 \mathrm{mg}$ of the original wood powder sample was inserted into the glass liner and placed in the pyrolyzer. The pyroprobe was initially set and held for $5 \mathrm{~s}$ at $100{ }^{\circ} \mathrm{C}$ (drying), and then ramped at $10{ }^{\circ} \mathrm{C} \mathrm{ms}^{-1}$ to the temperatures listed in Table 1, which were held for another $5 \mathrm{~s}$. The separation was provided by a $30 \mathrm{~m} \times 0.25 \mathrm{~mm} \times 0.25 \mu \mathrm{m}$ (internal diameter) HP-5MS fused silica capillary column. Before chromatographic separation, the temperature of the chromatographic column was held at $60{ }^{\circ} \mathrm{C}$ for 1 min, and then increased at $16{ }^{\circ} \mathrm{C} \min ^{-1}$ to $280{ }^{\circ} \mathrm{C}$. The capillary column was maintained at $280{ }^{\circ} \mathrm{C}$ for $2 \mathrm{~min}$. The injector temperature was $280{ }^{\circ} \mathrm{C}$ in split mode. Helium, at a flow of $2 \mathrm{~mL} \mathrm{~min}^{-1}$, was used as the carrier gas. The end of the column was inserted in the ion source of the mass selection detector 5975C (Agilent Technologies, Inc. Wilmington, USA) operated in electron impact ionization mode. The data acquisition system operated using ChemStation E 02.01.1177 software, and the released compounds were identified based on the NIST and Wiley electronic libraries.

\section{Kinetic analysis}

For the model-fitting procedure, the following eight mechanisms were assumed.

These are one-, two-, and three-step mechanisms assuming either parallel or competitive parallel reaction pathways. In the parallel reaction pathways, the initial biomass/wood portions (B) are considered separate. Each mechanism accounts for the production of volatile $(\mathrm{V})$, char $(\mathrm{CH})$, and intermediate portions (I).

Mechanism A is a one-step mechanism describing wood transformation into char, releasing volatiles. This mechanism was selected as the simplest one for use in the initial stages of modelling ${ }^{3,37,38}$. Mechanisms B are two-step and three-step mechanisms describing wood transformation via parallel and competitive parallel steps. For example, the competing mechanism B1 has been considered by many authors as much more relevant than the onestep mechanism ${ }^{1,22,39,40}$. Many modifications of this mechanism have been presented, but the general skeleton of two competitive steps remains unchanged. Mechanisms $\mathrm{C}$ are three-step mechanisms including an intermediate step with or without the production of volatiles. For example, mechanism $\mathrm{C} 1$ is the extension of mechanism B1 with an additional component, the intermediate. The original extension was made from the Kilzer-Broido mechanism by Bradburry et $a .^{2}{ }^{2}$, where the intermediate was produced directly from cellulose without any volatiles being released. Mechanism C2 was presented recently by $\mathrm{Wu}$ et $a l .{ }^{20}$ The majority of the selected mechanisms were described from a mathematical standpoint and applied by Font et al. ${ }^{41}$ and Aracil et al. ${ }^{42}$

Because the portions of released volatiles are unknown, the only experimental variable that can be compared against the computed one is the mass loss, i.e. the TG curve. Depending on the number of reaction steps that produce volatiles, the mass of the sample is computed as follows: mechanism A:

$$
m_{\text {sample }}=m_{\text {original }}-m_{\text {volatiles }}=m_{\text {original }}-v \alpha m_{\text {original }}
$$

mechanisms B1 and B2:

$$
m_{\text {sample }}=m_{\text {original }}-m_{\text {volatiles } 1}-m_{\text {volatiles } 2}=m_{\text {original }}-v_{1} \alpha_{1} m_{\text {original }}-v_{2} \alpha_{2} m_{\text {original }}
$$

mechanisms B3 and B4:

$$
m_{\text {sample }}=m_{\text {original }}-m_{\text {volatiles } 1}-m_{\text {volatiles } 2}-m_{\text {volatiles } 3}=m_{\text {original }}-v_{1} \alpha_{1} m_{\text {original }}-v_{2} \alpha_{2} m_{\text {original }}-v_{3} \alpha_{3} m_{\text {original }}
$$

mechanisms $\mathrm{C} 1$ and $\mathrm{C} 2$ :

$$
m_{\text {sample }}=m_{\text {original }}-m_{\text {volatiles } 1}-m_{\text {volatiles } 2}=m_{\text {original }}-v_{1} \alpha_{1} m_{\text {original }}-v_{2} \alpha_{2} m_{\text {int ermediate }}
$$

mechanism C3:

$$
m_{\text {sample }}=m_{\text {original }}-m_{\text {volatiles } 1}-m_{\text {volatiles } 12}-m_{\text {volatiles } 2}=m_{\text {original }}-v_{1} \alpha_{1} m_{\text {original }}-v_{12} \alpha_{12} m_{\text {original }}-v_{2} \alpha_{2} m_{\text {intermediate }}
$$

where $m_{\text {sample }}$ is the sample mass, $m_{\text {original }}$ is the original sample mass at time equal to zero, $m_{\text {volatiles } 1}, m_{\text {volatiles } 12}$, $m_{\text {volatiles } 2}$ are the volatile mass of the given reaction step. 
A

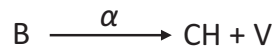

B1

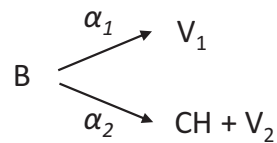

B2

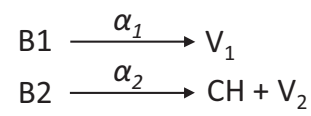

C1

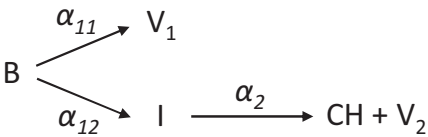

C2

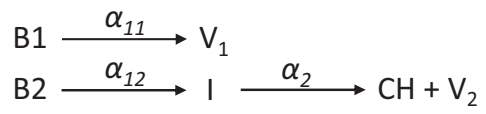

C3

Fig. 4 - Selected mechanisms of wood pyrolysis for the model-fitting procedure

Generally, the sample mass equals the original sample mass minus the volatile mass with the corresponding final mass fractions $v_{1}, v_{12}$, and $v_{2}$, while $\alpha_{1}, \alpha_{12}$, and $\alpha_{2}$ are conversions of the given reaction step.

The mass of the intermediate is computed as

$$
m_{\text {intermediate }}=\left(1-v_{1}\right) \alpha_{12} m_{\text {original }}
$$

The rate of the thermal decomposition of biomass is defined by equation

$$
\frac{\mathrm{d} \alpha}{\mathrm{d} t}=A \exp \left(\frac{-E}{R T}\right)(1-\alpha)^{n}
$$

where $\alpha$ is the extent of the conversion, and $t$ is the time. The temperature dependence of the process is parameterized through the Arrhenius equation, where $A$ is the pre-exponential (frequency) factor, $E$ is the activation energy of the reaction, and $R$ is the universal gas constant. The rate equations were derived in the same way as by Font et al. ${ }^{41}$ and Aracil et al. ${ }^{42}$

The parameters to be optimized are $A, E, n$, and $v$, indexed according to the mechanism used. Integration of the rate equations provides the respective conversions. The computed sample mass (Eqs. 1-6) has to be recalculated to conversion as defined by the equation

$$
\alpha=\frac{m_{\text {orginal }}-m_{\text {sample }}}{m_{\text {orginal }}-m_{f}}=\frac{v}{v_{t}}
$$

The objective function (OF) to be minimized is defined as a sum of square differences between the experimental and the calculated conversion time derivatives considering all heating rates

$$
O F=\sum_{j}^{\beta} \sum_{i}^{p}\left(\left(\frac{\mathrm{d} a}{\mathrm{~d} t}\right)_{i, \exp }-\left(\frac{\mathrm{d} a}{\mathrm{~d} t}\right)_{i, c a l}\right)_{\beta}^{2}
$$

where $p$ is the total number of points for the given heating rate $\beta$.
Optimization was performed employing Matlab computational software. Integration of the rate equations was performed using the ode $15 \mathrm{~s}$ function, and minimization of the OF was performed by the fmincon function. To ensure that the global minimum of the OF is reached, a procedure considering various initial estimates was used.

\section{Results and discussion}

\section{TG and elemental analysis}

TG curves obtained at the heating rates of 2,5 , 10,15 , and $20{ }^{\circ} \mathrm{C} \mathrm{min}^{-1}$ and the first derivative of the TG curves (DTG curves) are depicted in Fig. 5. As can be seen from the DTG curves, thermal degradation progressed through the following three peaks: the first one, up to about $160{ }^{\circ} \mathrm{C}$, corresponds to sample drying with approximately $5 \%$ mass loss; the second one, in the temperature interval of 250 $320{ }^{\circ} \mathrm{C}$, mainly represents the degradation of hemicelluloses; and the third one, in the temperature interval of $320-400{ }^{\circ} \mathrm{C}$, mainly represents the degradation of cellulose. In the temperature interval of $250-400{ }^{\circ} \mathrm{C}$, active pyrolysis with approximately $70 \%$ mass loss was observed. Above $400{ }^{\circ} \mathrm{C}$, passive pyrolysis took place. However, lignin degradation occurred in the broad temperature interval of 200-500 ${ }^{\circ} \mathrm{C}$ and could not be distinguished from hemicellulose and cellulose degradation. The peak complexity, more obvious at higher heating rates, is due to the relatively high content of hemicellulose degrading at lower temperatures than cellulose.

Considering the elemental composition, it is obvious that the mass fraction of $\mathrm{C}$ increased with the increasing temperature at the expense of the mass fraction of $\mathrm{H}$ (Fig. 6). This trend confirms that the solid residue was more charred due to the increasing temperature. 

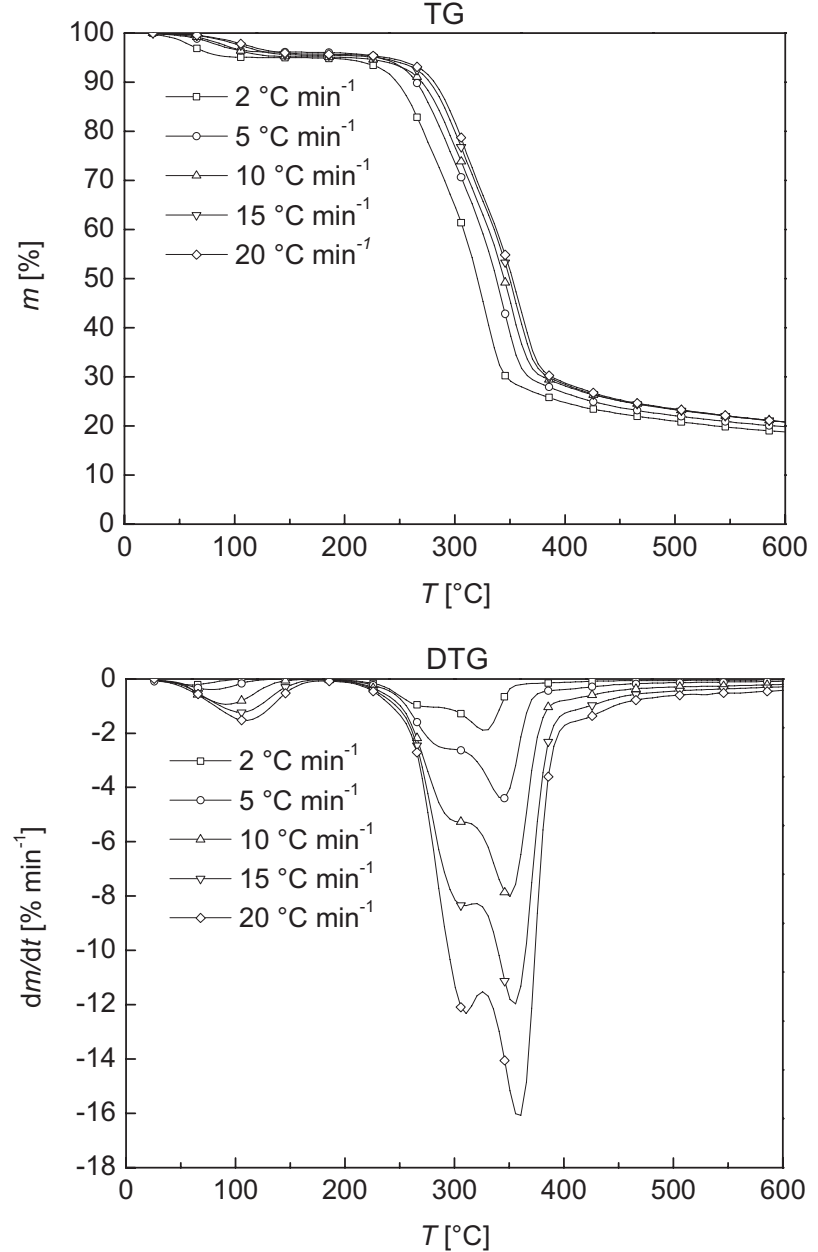

Fig. 5 - TG and DTG curves of beech pyrolysis at five heating rates and an argon flow rate of $60 \mathrm{~mL} \mathrm{\textrm {min } ^ { - 1 }}$

\section{NMR analysis}

The results of the ${ }^{13} \mathrm{C}$ NMR analysis of solid residues of beech are shown in Fig. 7. Comparing the NMR spectra for individual temperatures, two distinct temperature sections can be identified, below and above $300{ }^{\circ} \mathrm{C}$. The spectra in the first section seemed to be identical; however, detailed inspection revealed some changes within this temperature range. The hemicellulose acetyl methyl (H1) signal as well as that of the hemicellulose acetyl carboxyl (H2) continuously decreased with the increasing temperature, which represents the release of acetyl groups. The highest temperature with a detectable hemicellulose signal was $320^{\circ} \mathrm{C}$. The cellulose signals in the spectra were the most obvious ones; cellulose C-6 (amorphous) (C1) and cellulose C-4 (amorphous) (C5) signals, representing amorphous cellulose, were both more evident at $300{ }^{\circ} \mathrm{C}$, while the cellulose C-6 (crystalline) (C2) and cellulose C-4 (crystalline) (C6) signals, representing crystalline cellulose, started to decrease between 270-290 ${ }^{\circ} \mathrm{C}$. This indicates the transformation of

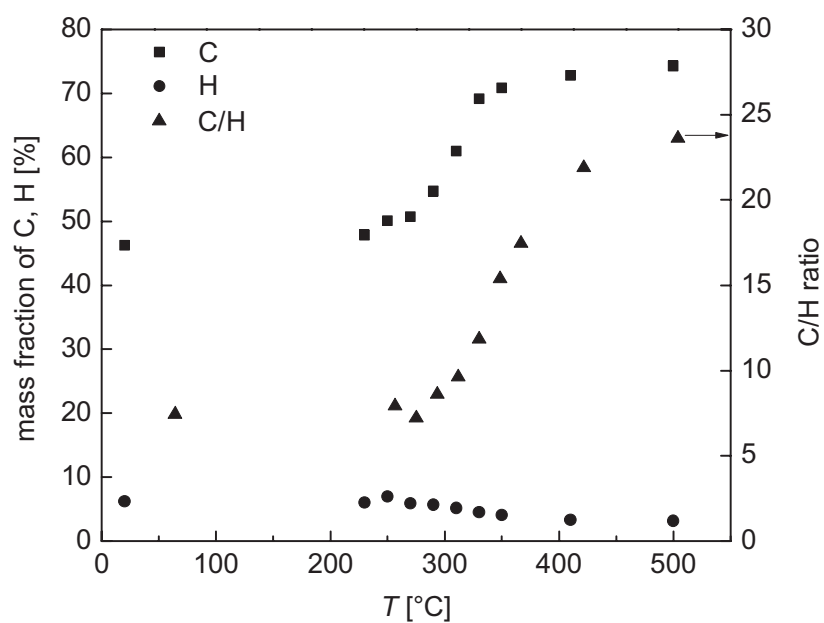

Fig. 6 - Mass fractions of $C$ and $H$ and $C / H$ ratio of solid residues for different final temperatures

the crystalline form into an amorphous one. The cellulose C-1 (C7) signal, representing cellulose as a whole, remained unchanged up to $300{ }^{\circ} \mathrm{C}$. Cellulose was the most degraded compound in the temperature range of $300-310{ }^{\circ} \mathrm{C}$. Only small residues remained at $320^{\circ} \mathrm{C}$.

The second most obvious signals in the spectra were those of lignins. The lignin methoxyl (L1) signal was quite persistent and became more obvious as the cellulose degraded at $320^{\circ} \mathrm{C}$. With a further temperature increase, this signal continuously decreased, reflecting the process of lignin demethoxylation. The lignin G-6 (L2) signal increased very slightly, together with that of the aromatic lignin signals as a whole in the chemical shift range of 115-160 ppm, which was even more evident from $310^{\circ} \mathrm{C}$. It can be concluded that this increasing signal is caused by lignin demethoxylation by the syringyl structure transformation, which corresponds with the previous statement. The lignin S-1 (ne), S-4 (ne) and G-1 (ne) (L3) signal was also of importance because both syringyl and guaiacyl units were present in their non-etherified form. An increase in this signal thus reflects the cleavage of $\beta-\mathrm{O}-4$ bonds between lignin dimers. This behaviour can be clearly seen above $290^{\circ} \mathrm{C}$. The lignin S-1 (e), S-4 (e) and G-1 (e) (L4) signal, representing the etherified forms, was then expected to decrease. Although this signal was quite low, its decrease was observed between $270-290{ }^{\circ} \mathrm{C}$. The behaviour of the last two lignin signals fits perfectly into the already drawn mosaic. The lignin S-3 (ne), S-5 (ne) and lignin G-3 (ne, e), G-4 (ne, e) signal (L5), representing both the etherified and the non-etherified forms, increased very distinctly from the lowest temperature up to $300{ }^{\circ} \mathrm{C}$, then it remained constant up to $320^{\circ} \mathrm{C}$, at which point it rapidly decreased. At the same time, the lignin S-3 (e), S-5 (e) signal 

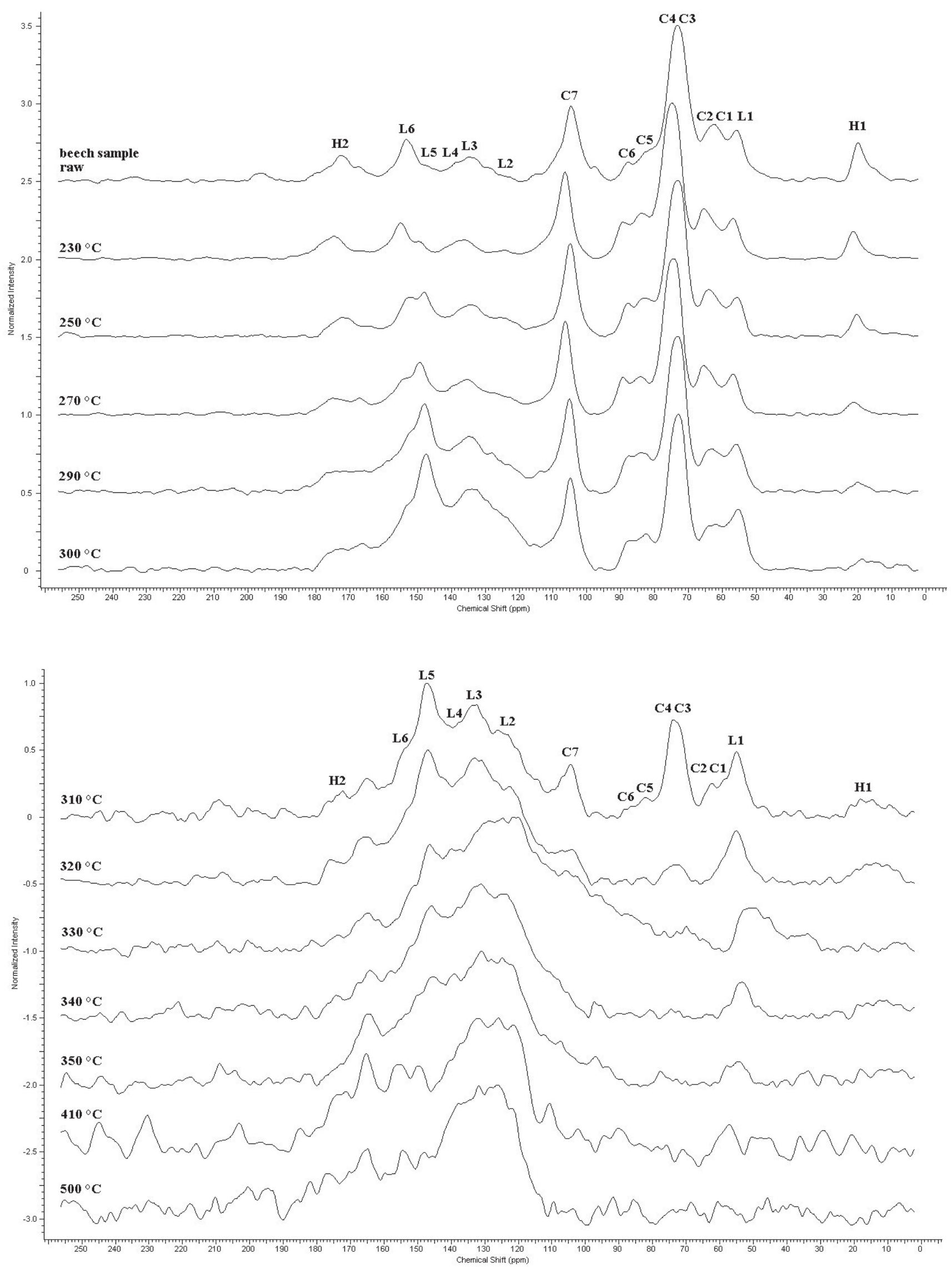

Fig. 7 - NMR spectra of solid residues of beech prepared at the temperatures in Table 1 
(L6), representing the etherified form, slightly decreased and merged with the increasing L5 signal. However, this behaviour can represent either the $\beta-\mathrm{O}-4$ bond cleavage or syringyl demethoxylation into guaiacyl. The following two facts support the lignin demethoxylation pathway: 1) the $\beta-\mathrm{O}-4$ bond cleavage was observed at temperatures not lower than $270-290{ }^{\circ} \mathrm{C}$, and 2) the lignin G-6 (L2) signal slightly increased, and the lignin S-3 (e), S-5 (e) signal (L6) slightly decreased at the lowest temperature. However, starting at the temperature range of $270-290{ }^{\circ} \mathrm{C}$, the $\beta-\mathrm{O}-4$ bond cleavage occurred, resulting in a more intensive L5 increase. Starting from $320{ }^{\circ} \mathrm{C}$, not only did the L1 signal decrease due to lignin demethoxylation, but also the L5 signal rapidly decreased. Given that, at this temperature, the L5 signal is assumed to consist of pure guaiacyl structure in its etherified or non-etherified form, its decrease means either its depolymerization into monomer units or the degradation of the guaiacyl monomer unit itself. At the last two temperatures, $410{ }^{\circ} \mathrm{C}$ and $500{ }^{\circ} \mathrm{C}$, signals in the chemical shift range of $110-140 \mathrm{ppm}$ were absolutely dominant; the original lignin structure had disappeared. At this point, only the charred residue, containing condensed aromatic structures, had remained.

\section{FTIR analysis}

Fig. 8 depicts the DTG curve with the so-called Gram-Schmidt intensity of beech pyrolysis at $20{ }^{\circ} \mathrm{C}$ $\mathrm{min}^{-1}$. The Gram-Schmidt intensity is based on vector analysis of the acquired interferogram, which allows plotting the total evolved gases detected by the spectrometer. Clearly, the Gram-Schmidt intensity corresponds with the DTG curve. The first peak at approximately $100{ }^{\circ} \mathrm{C}$ represents the water vapour release. The second complex peak confirms the release of volatiles in two steps during active pyrolysis.

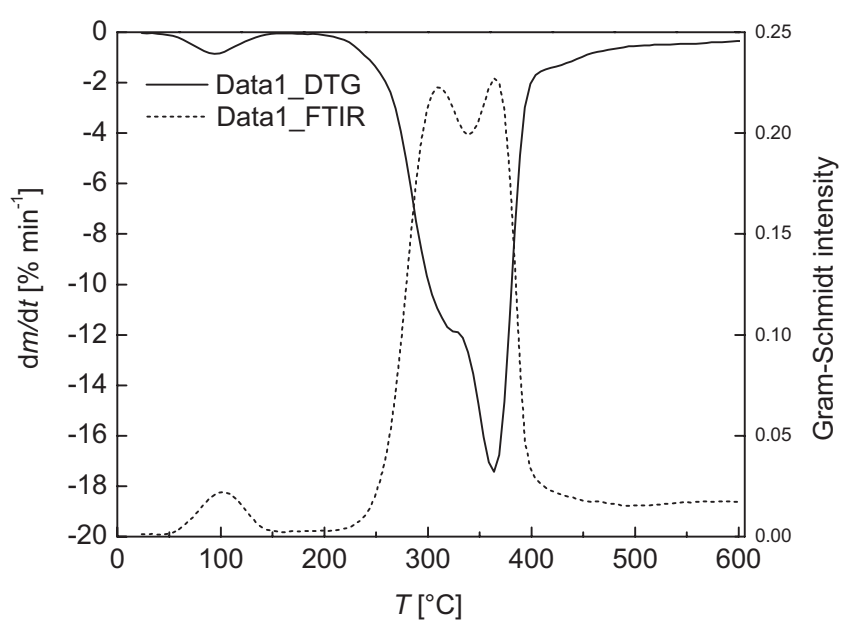

F ig. 8 - DTG curve and Gram-Schmidt intensity of beech pyrolysis at $20{ }^{\circ} \mathrm{C} \mathrm{min}^{-1}$
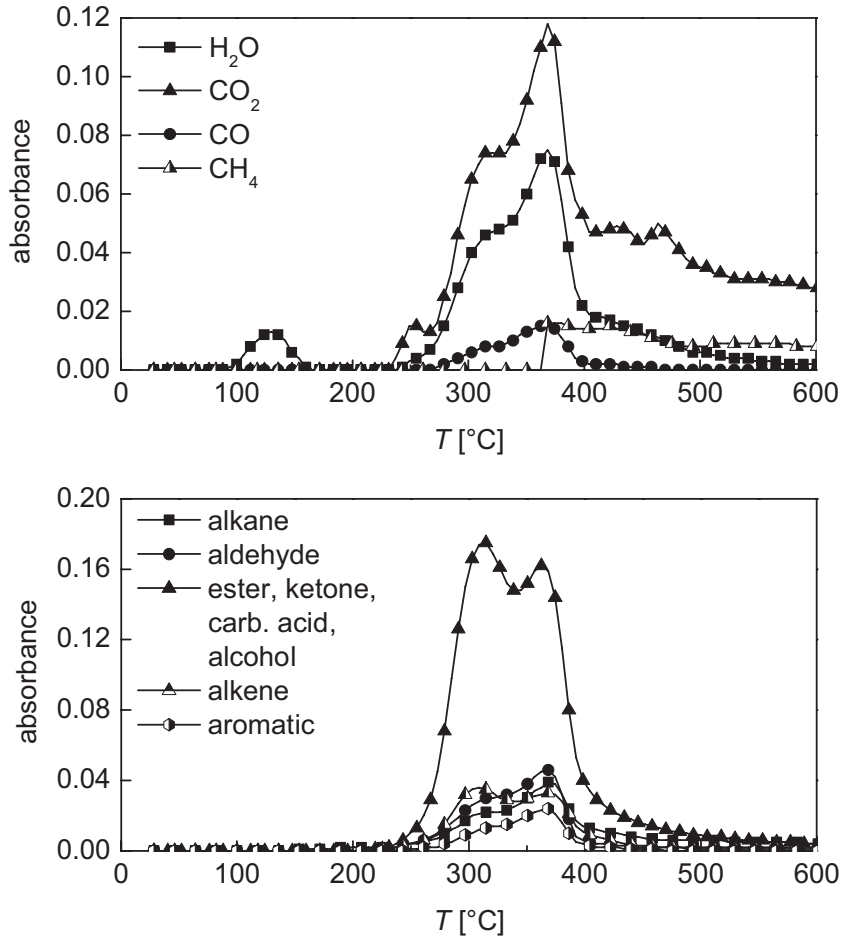

Fig. 9 - TG-FTIR pyrolysis product evolution of beech sample at a heating rate of $20^{\circ} \mathrm{C} \mathrm{min}^{-1}$

Fig. 9 depicts the evolution of pyrolysis products identified in the spectrum of beech wood. Individual compounds identified are water vapour, carbon dioxide, carbon monoxide, and methane. The functional groups identified include alkanes, alkenes, aldehydes, ketones, alcohols, esters, carboxylic acids, and aromatics. With increasing temperatures, water vapour is released due to drying. Above approximately $250{ }^{\circ} \mathrm{C}$, the intensity of volatile component absorbance increases over the maximum. The initial stages of methane release were very difficult to determine due to peak fusion. According to Liu et al. ${ }^{36}$, water vapour, carbon dioxide, carbon monoxide, methane, alcohols, aldehydes or acetic acids, phenols, and other paraffin gases were identified during pine sawdust pyrolysis. The progress of the released volatile absorbance and the temperature interval of their evolution are similar to that observed in this work.

Carbon monoxide is the product of ether groups present in lignin and/or ether compounds produced in the secondary cracking of volatiles, and methane is formed by the methoxy and methylene groups cracking. Water vapour originated from the bulk water, bound water, and crystallization water. Additionally, water is also formed by cracking, the reaction of oxygen functional groups at higher temperatures ${ }^{44}$ or by dehydratation of the hydroxy group in cellulose and hemicellulose ${ }^{45}$. The reported maximum peak of carbon dioxide at $360{ }^{\circ} \mathrm{C}$ is in agreement with the results obtained in this study. The 
residual release of carbon dioxide starting at $400{ }^{\circ} \mathrm{C}$ is probably connected with the polymerization reactions of coking in the solid phase ${ }^{43}$. The results of poplar sawdust pyrolysis were published by $\mathrm{Gu}$ et $a l .{ }^{46}$ The pyrolysis process was divided into the following three steps: below $250{ }^{\circ} \mathrm{C}$, production of water vapour, carbon dioxide, carbon monoxide, and methane; in the range of $250-500{ }^{\circ} \mathrm{C}$, production of aldehydes, ketones, acetic acids, furans, alcohols or phenols; and above $500{ }^{\circ} \mathrm{C}$, carbonization and char formation processes result in low amounts of carbon dioxide. Speculative pathways for the mechanisms of cellulose, hemicellulose, and lignin pyrolysis were also presented. A more realistic model than that presented by Diebold J.P. ${ }^{47}$, assuming the transformation of active cellulose into char without carbon dioxide release at the same temperature, was proposed. The first carbon dioxide signal was detected at approximately $250{ }^{\circ} \mathrm{C}$, which is consistent with the results presented in this work, while carbon dioxide was detected already at 230 ${ }^{\circ} \mathrm{C}$ (Fig. 9). However, based on the results presented in this study, water vapour, carbon dioxide, as well as esters, ketones, carboxylic acids, and alcohols are released at slightly lower temperatures than carbon monoxide, methane, alkane, alkene, aldehyde, and aromatics.

\section{Py-GC/MS analysis}

Compounds identified in pyrograms were divided into the following groups: alcohols, aldehydes, alkanes, alkenes, aromatics, carboxylic acids, esters, ethers, heterocycles, ketones, others (alkynes), and saccharides. The peak area of each group was computed as a summation of the individual peak areas of the corresponding compounds; the peak areas of the groups were normalized to unity for each temperature. Fig. 10 depicts the distribution of the groups of compounds of pyrolysis products identified in pyrograms obtained at the temperatures listed in Table 1.

The pyrograms were expected to show increasing numbers of compounds with increasing temperatures. As can be seen in Fig. 10, a large number of groups are present at lower temperatures, especially at $250{ }^{\circ} \mathrm{C}$ and $310{ }^{\circ} \mathrm{C}$. For example, 16 compounds were identified in the pyrogram obtained at $250{ }^{\circ} \mathrm{C}$, while 57 were observed in that at $500{ }^{\circ} \mathrm{C}$. Although no distinct trend can be seen in Fig. 10, there are similar portions of heterocycles and ketones starting at $330^{\circ} \mathrm{C}$. When comparing individual compounds, the pyrogram obtained at $320{ }^{\circ} \mathrm{C}$ showed more than twice the number of compounds than that obtained at $310{ }^{\circ} \mathrm{C}$. This radical change
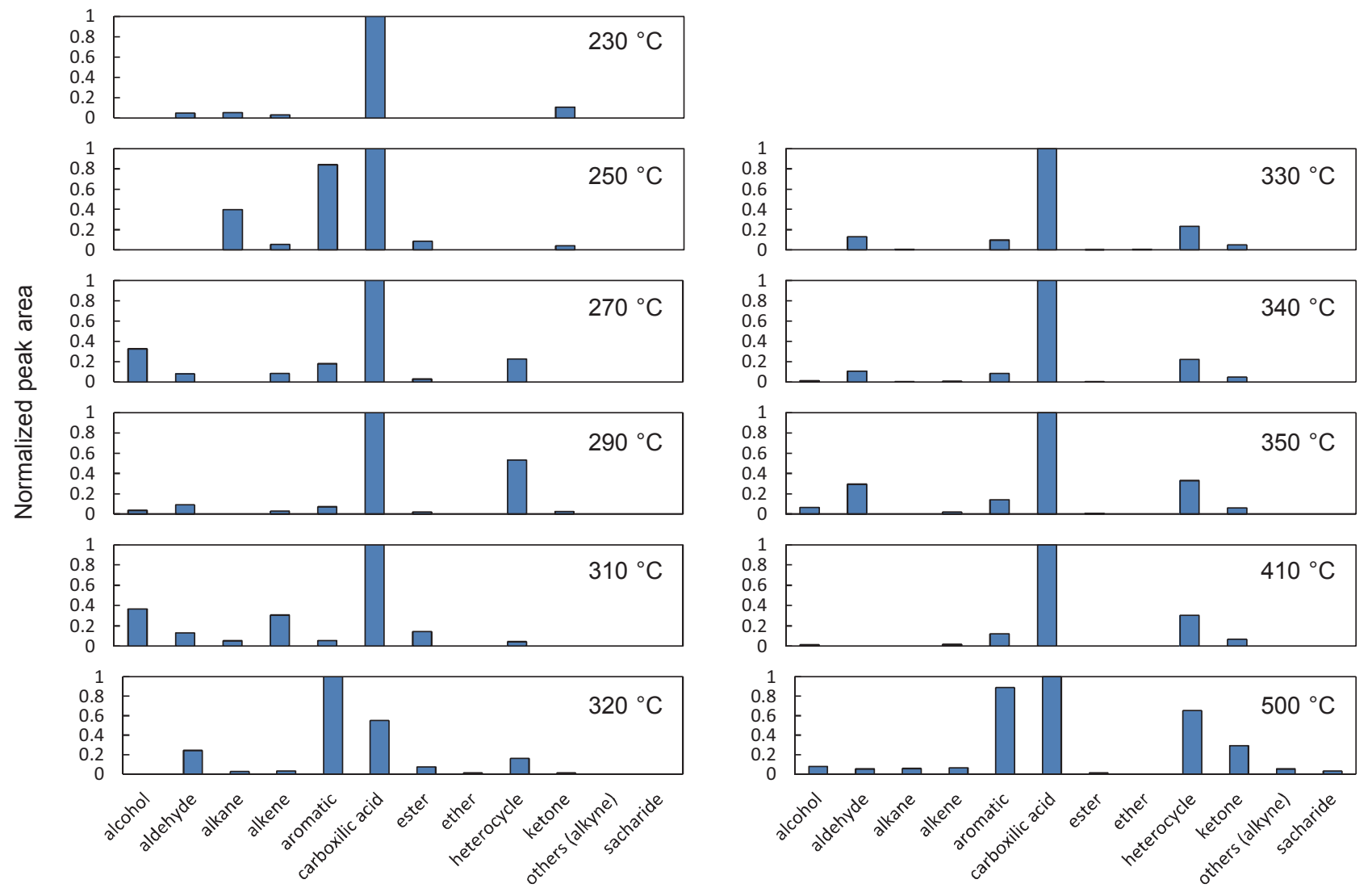

Fig. 10 - Pyrolysis product distribution from Py-GC/MS ion chromatograms of beech sample for temperatures listed in Table 1 
can also be seen in the NMR spectra (Fig. 7), where most of the cellulosic content is degraded. Above $320{ }^{\circ} \mathrm{C}$, the pyrograms showed an increasing number of individual aromatics. Py-GC/MS analysis of pine sawdust products pyrolyzed at $550{ }^{\circ} \mathrm{C}$ was reported $^{43}$. In total, 35 compounds were identified, mainly permanent gases, acetaldehyde, acetic acid, and acetic anhydride. In lower amounts, levoglucosan, aldehydes, ketones, alcohols, and phenolic compounds were also present. Acetic acid is formed by the elimination of acetyl groups of hemicellu$\operatorname{los} \mathrm{e}^{48}$. Levoglucosan is probably produced by the breakdown of glycosidic bonds and the rearrangement of cellulose monomers. Consequently, cyclohexanone is produced by the dehydration of levoglucosan ${ }^{43}$. Phenolic compounds are produced by the decomposition of lignin ${ }^{49}$. Py-GC/MS analysis of poplar sawdust products obtained at $600{ }^{\circ} \mathrm{C}$ was presented by $\mathrm{Gu}$ et $a .^{46}$ with the main identified compounds being carbonyls (aldehydes, ketones, and acids), furans, and phenols. Also, the pyrolysis products contained other aromatics.

\section{Kinetic analysis}

The kinetic parameters of the integral isoconversional method of beech pyrolysis were reported by Anca-Couce et al. ${ }^{50}$ The mean value of activation energy determined was $183.7 \mathrm{~kJ} \mathrm{~mol}^{-1}$ (range of 169.6-193.1). The mean value of the activation energy was shown to be $284.9 \mathrm{~kJ} \mathrm{~mol}^{-1}$ (range of 246.5-350.0) and $203.0 \mathrm{~kJ} \mathrm{~mol}^{-1}$ (range of 187.2210.9), respectively (Koufopanos et al. ${ }^{27}$ and Volker S. and Rieckmann $\mathrm{T}^{51}$ ). The mean values of the kinetic parameters were used as the initial values for the model fitting method. Table 3 summarizes all kinetic mechanisms with their corresponding OF values after the optimization procedure.

The lowest values of OF were obtained with B4. However, up to B1, the difference between the OFs was not very significant. In Fig. 11, experi-

Table 3 -Reaction mechanisms for the model-fitting procedure with the corresponding $O F$ values (from the lowest $O F$ )

\begin{tabular}{cc}
\hline Mechanisms/model & OF $\left[\mathrm{s}^{-2}\right]$ \\
\hline B4 & $2.58 \cdot 10^{-5}$ \\
C1 & $2.66 \cdot 10^{-5}$ \\
C3 & $2.71 \cdot 10^{-5}$ \\
B2 & $2.80 \cdot 10^{-5}$ \\
C2 & $2.83 \cdot 10^{-5}$ \\
B1 & $3.96 \cdot 10^{-5}$ \\
B3 & $3.96 \cdot 10^{-5}$ \\
A & $6.68 \cdot 10^{-5}$ \\
\hline
\end{tabular}

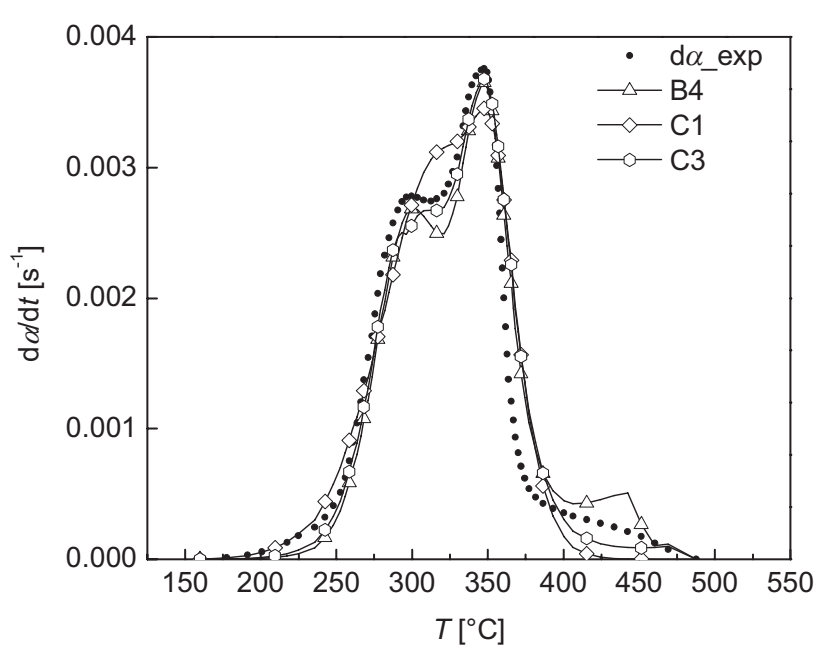

Fig. 11 - Experimental and calculated da/dt curves for mechanisms B4, C1, and $C 3$ at a heating rate of $20{ }^{\circ} \mathrm{C} \mathrm{min}^{-1}$

mental and calculated $\mathrm{d} \alpha / \mathrm{d} t$ curves for mechanisms B4, C1, and C3 are depicted at a heating rate of 20 ${ }^{\circ} \mathrm{C} \mathrm{min}^{-1}$. In the case of $\mathrm{B} 4$, a third peak at the end of the process was observed. This additional peak was caused by the incorporation of the third portion of volatiles. Mechanism C1 does not sufficiently fit the peak complexity mainly in the range of 280-350 ${ }^{\circ} \mathrm{C}$. Mechanism C3 incorporates the third portion of volatiles, but the third peak is positioned in the first part of the complex peak causing its deformation. As previously discussed, these mechanisms are not appropriate as they do not fit the data.

Based on the OF value, mechanisms B2 and C2 were tested. In Fig. 12, experimental and calculated $\mathrm{d} \alpha / \mathrm{d} t$ curves for mechanisms $\mathrm{B} 2$ and $\mathrm{C} 2$, respectively, are depicted for all heating rates. Both mechanisms fit the experimental data satisfactorily with very close $\mathrm{OF}$ values. However, mechanism $\mathrm{C} 2$ best describes the peak complexity at the highest heating rate.

The optimized parameters for mechanisms B2 and $\mathrm{C} 2$ are summarised in Table 4.

The summation of $v_{1}$ and $v_{2}$ in mechanisms B2 and $\mathrm{C} 2$ are close to the experimental value of 0.76 , which is the mean experimental value of the final mass fraction of volatiles for all five heating rates of the TG measurement. The values of the activation energy are consistent with those reported for the parallel reaction scheme for cellulose ${ }^{52}$. The maximum conversion rate of wood thermal decomposition can be attributed to cellulose. Considering individual reaction pathways, the values of the kinetic parameters for mechanism B2 are in perfect agreement with the reported data by Mamleev et $a l .{ }^{26}$ Regarding the intermediate step in mechanism $\mathrm{C} 2$, the optimized parameters are in good agreement with those reported by Bradburry et al. ${ }^{2}$, espe- 

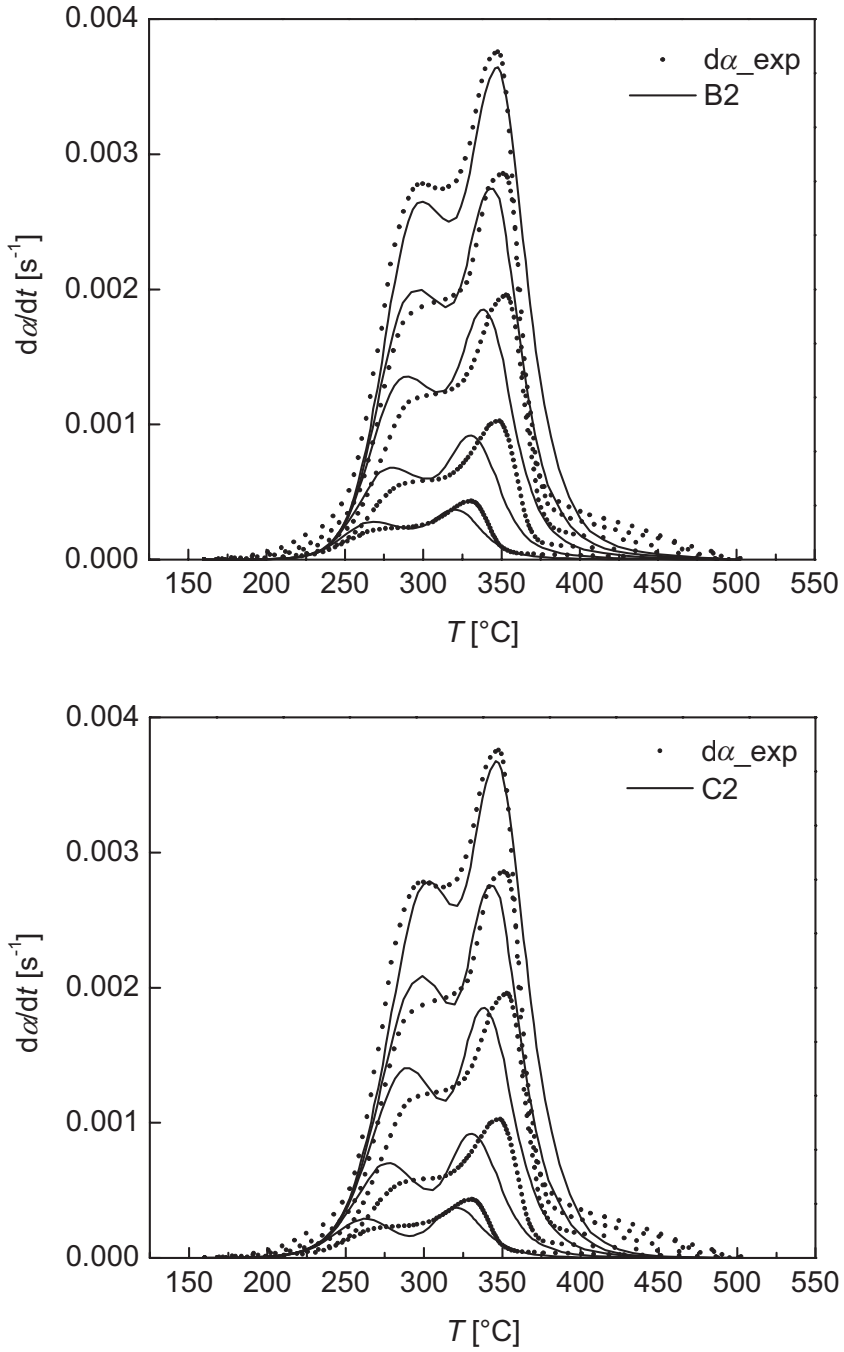

Fig. 12 - Experimental and calculated da/dt curves for mechanisms $B 2$ and $C 2$ for heating rates of 2, 5, 10,15 , and $20^{\circ} \mathrm{C} \mathrm{min}^{-1}$

cially the value of the pre-exponential factor. The mechanism assuming no production of volatiles in the first step and a cellulose sample were used; the transformation to the intermediate seems to have

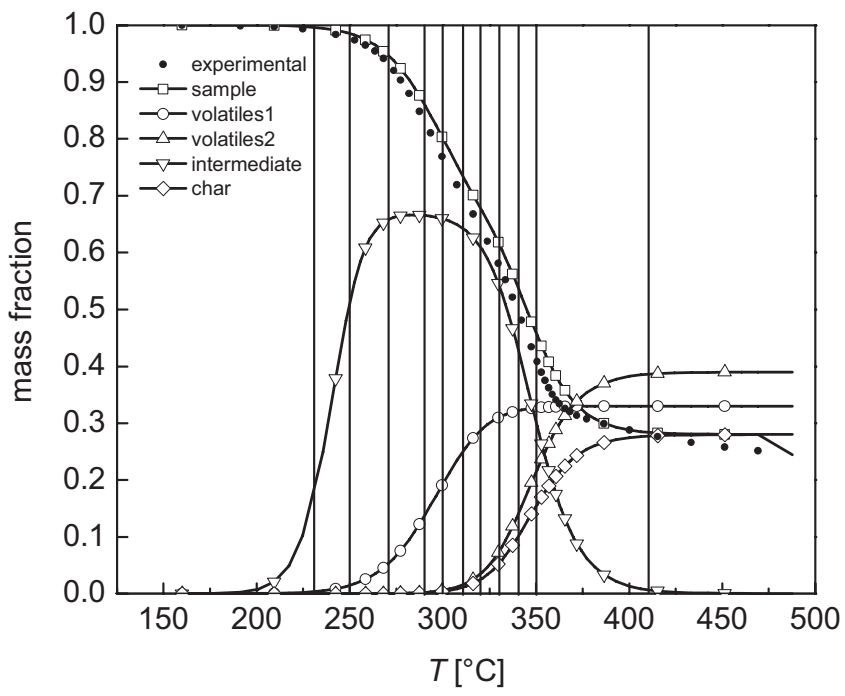

Fig. 13 - Mass fractions of the components in mechanism $\mathrm{C} 2$ at a heating rate of $20^{\circ} \mathrm{C} \mathrm{min}-1$ with gridlines corresponding to the temperatures in Table 1

reasonably similar values for the kinetic parameters. However, the introduction of the intermediate step did not result in lower OF values in mechanism C2. In this case, to justify the necessity of the next reaction step, additional experimental information is needed.

To simulate the concentration progress of individual components, mainly those of the intermediate, the mass fractions of each component in mechanism $\mathrm{C} 2$ were computed for each temperature at the heating rate of $20{ }^{\circ} \mathrm{C} \mathrm{min}{ }^{-1}$ (Fig. 13). For better comparison with the NMR results, gridlines corresponding to the temperatures in Table 1 are shown, which should be interpreted as the mass fraction of each component at the given temperature instead of the time trend of these mass fractions.

The mass fraction of the intermediate increased with the increasing temperature and decreasing sample mass, followed by volatiles V1 for mechanism C2. The intermediate was present in the tem-

Table 4 -Optimized parameters for mechanisms B2 and C2 with the corresponding OF values

\begin{tabular}{|c|c|c|c|c|c|}
\hline \multicolumn{6}{|c|}{ Mechanism B2 } \\
\hline$A_{1}\left[\mathrm{~s}^{-1}\right]$ & & $7.48 \cdot 10^{15}$ & \multicolumn{2}{|c|}{$A_{2}\left[\mathrm{~s}^{-1}\right]$} & $2.72 \cdot 10^{19}$ \\
\hline$E_{1}\left[\mathrm{~kJ} \mathrm{~mol}^{-1}\right]$ & & 190.7 & \multicolumn{2}{|c|}{$E_{2}\left[\mathrm{~kJ} \mathrm{~mol}^{-1}\right]$} & 250.0 \\
\hline$n_{1}$ & & 3.00 & \multicolumn{2}{|c|}{$n_{2}$} & 1.80 \\
\hline$v_{1}$ & & 0.40 & \multicolumn{2}{|c|}{$v_{2}$} & 0.31 \\
\hline \multicolumn{6}{|c|}{ Mechanism C2 } \\
\hline$A_{11}\left[\mathrm{~s}^{-1}\right]$ & $7.60 \cdot 10^{11}$ & $A_{12}\left[\mathrm{~s}^{-1}\right]$ & $8.15 \cdot 10^{19}$ & $A_{2}\left[\mathrm{~s}^{-1}\right]$ & $2.98 \cdot 10^{19}$ \\
\hline$E_{1}\left[\mathrm{~kJ} \mathrm{~mol}^{-1}\right]$ & 148.8 & $E_{12}\left[\mathrm{~kJ} \mathrm{~mol}{ }^{-1}\right]$ & 210.9 & $E_{2}\left[\mathrm{~kJ} \mathrm{~mol}^{-1}\right]$ & 250.0 \\
\hline$n_{11}$ & 1.45 & \multirow{2}{*}{$n_{12}$} & \multirow{2}{*}{1.55} & $n_{2}$ & 2.02 \\
\hline$v_{1}$ & 0.33 & & & $v_{2}$ & 0.39 \\
\hline
\end{tabular}


perature range of $200-400{ }^{\circ} \mathrm{C}$. While the intermediate decomposed, volatiles V2 for mechanism C2 were released, forming char. The final mass fraction of volatiles V1 was 0.33 , and that of volatiles V2 was 0.39 . The change in the composition of the solid residue represented by the calculated mass fractions of individual components was compared with the experimental data from NMR and FTIR analyses. The aim was to decide whether mechanism $\mathrm{C} 2$ is more realistic than mechanism B2.

According to the simulation results (Fig. 13), the only change observed above $230^{\circ} \mathrm{C}$ was the formation of the intermediate. In the NMR spectra (Fig. 7), this temperature represents only the process of lignin demethoxylation. Thus, it can be concluded that the presence of the intermediate is connected to the presence of the lignin structure. In the temperature interval $230-300{ }^{\circ} \mathrm{C}$, changes mainly connected with the release of volatiles V1 were observed (Figs. 7-10). Considering the release of volatiles only, this temperature interval is characterized by the cleavage of hemicellulose acetyl groups and by lignin demethoxylation. At $320{ }^{\circ} \mathrm{C}$, the last remaining residues of hemicellulose and cellulose can be found, and volatiles V2 are present (Figs. 7-10). This means that the release of volatiles V2 is not connected with the cleavage of hemicellulose acetyl groups. However, further lignin demethoxylation and cleavage of the $\beta-\mathrm{O}-4$ bonds in lignin occur, which means that the release of volatiles V2 is connected with these processes. Along with the release of volatiles V2, char is formed. In NMR, this is probably accompanied with the cleavage of the $\beta-\mathrm{O}-4$ bonds or lignin monomer unit degradation, leading to lignin-derived aromatic structures. According to the simulation results (Fig. 13), intermediate degradation is finished above $400{ }^{\circ} \mathrm{C}$, so further formation of char is accompanied by the formation of condensed aromatic structures.

According to the aforementioned facts, the intermediate represents a solid structure that is neither a raw sample nor charred residue. This structure continuously undergoes transformations connected with the lignin structure. Thus, mechanism $\mathrm{C} 2$ is more realistic than mechanism B2 because the direct transformation of the initial portion of biomass/ wood to char, as stated in mechanism B2, is rather improbable. The presence of the intermediate in mechanism $\mathrm{C} 2$ prolongs the process.

\section{Conclusions}

In this work, the kinetic mechanisms of wooden biomass thermal decomposition were differentiated based on experimental results. The process of thermal decomposition was investigated by thermo- gravimetry. In addition, analytical techniques suitable for the investigation of compositional and structural changes of the decomposed material and the evolved products were employed, and a suitable kinetic approach for the determination of kinetic parameters was proposed.

Optimization of kinetic parameters was performed employing three kinetic approaches, and mechanism C2 was found to provide a slightly better fit to the experimental data than mechanism B2, with comparable OF values. The selection of mechanism C2 was supported by the experimental NMR results of solid residues prepared at distinct temperatures of the TG curve. The NMR results showed that the introduction of an intermediate into the reaction scheme of wood thermal decomposition into char and volatiles V2 was a reasonable step.

The mass fractions of each component in the solid and gas phase in mechanism C2 were computed as a function of temperature, and the results were compared with those of NMR, TG-FTIR and PyGC/MS analyses. It can be recommended that the presence of an intermediate is connected with the lignin structure starting with the process of lignin demethoxylation. The formation of volatiles V1 is likely connected with the release of hemicellulose acetyl groups and lignin demethoxylation. In contrast, the formation of volatiles V2 is not connected with the release of hemicellulose acetyl groups but rather with further lignin demethoxylation and the cleavage of the $\beta-\mathrm{O}-4$ bonds in lignin. The formation of char is probably accompanied by the cleavage of the $\beta-\mathrm{O}-4$ bonds in lignin or lignin monomer unit degradation leading to lignin-derived aromatic structures. The intermediate represents a solid structure that is neither a raw sample nor charred residue, and continuously undergoes transformations connected with the lignin structure.

Further investigation of the solid and gas phase during thermal decomposition of wood biomass would provide better understanding of the core mechanisms involving an intermediate. Studies employing also TG-GC/MS, ${ }^{1} \mathrm{H}$ NMR, ${ }^{13} \mathrm{C} \mathrm{NMR}$ or two-dimensional heteronuclear single quantum coherence (2D-HSQC) NMR, for instance, can shed more light onto the reaction mechanisms.

\section{ACKNOWLEDGEMENTS}

This work was supported by the Slovak Scientific Agency, Grant No. VEGA 1/0757/13 and by the $O P$ Research and Development of the project $\mathrm{Na}$ tional Centre for Research and Application of Renewable Energy Sources, ITMS 26240120016, co-financed by the Fund of European Regional Development. 


\section{Sy m bols}

$m_{\text {original }}$ - initial mass of sample during the process, $\mathrm{kg}$

$m_{f} \quad-$ final mass of sample during the process, $\mathrm{kg}$

$m_{\text {sample }}-$ mass of sample during the process, $\mathrm{kg}$

$m_{\text {volatiles }}-$ mass of volatiles, $\mathrm{kg}$

$E^{\text {volatiles }}-$ activation energy of the reaction, $\mathrm{J} \mathrm{mol}^{-1}$

$A \quad$ - pre-exponential (frequency) factor, $\mathrm{s}^{-1}$

$R \quad-$ gas constant, $\mathrm{J}_{\mathrm{mol}}^{-1} \mathrm{~K}^{-1}$

$T \quad$ - temperature, $\mathrm{K}$

$n \quad-$ order of reaction step

$p \quad-$ total number of experimental points

$O F \quad-$ objective function defined by equation (9), $\mathrm{s}^{-2}$

$t \quad-$ time, $\mathrm{s}$

$v \quad-$ mass fraction of volatiles during the process

$v_{t} \quad-$ final mass fraction of volatiles

$\alpha-$ extent of the conversion

$\beta \quad-$ heating rate, $\mathrm{K} \mathrm{s}^{-1}$

\section{References}

1. Kilzer, F. J., Broido, A., Speculations on the nature of cellulose pyrolysis, Pyrodynamics 2 (1965) 151.

2. Bradburry, A. G. W., Sakai, Y., Shafizadeh F., A kinetic model for pyrolysis of cellulose, Journal of Applied Polymer Science 23 (1979) 3271.

doi: http://dx.doi.org/10.1002/app.1979.070231112

3. Antal, M. J. Jr., Várhegyi, G., Cellulose pyrolysis kinetics: the current state of knowledge, Industrial and Engineering Chemistry Research 34 (1995) 703. doi: http://dx.doi.org/10.1021/ie00042a001

4. Lédé, J., Cellulose pyrolysis kinetic: An historical review on the existence and role of intermediate active cellulose, Journal of Analytical and Applied Pyrolysis 94 (2012) 17. doi: http://dx.doi.org/10.1016/j.jaap.2011.12.019

5. Shafizadeh, F., Introduction to pyrolysis of biomass, Journal of Analytical and Applied Pyrolysis 3 (1982) 283. doi: http://dx.doi.org/10.1016/0165-2370(82)80017-X

6. Wang, S., Bin, R., Gongxin, D., Wuxing, S., Jinsong, Z., Kunzan, Q., Pyrolysis mechanism study of minimally damaged hemicellulose polymers isolated from agricultural waste straw samples, Bioresource Technology 190 (2015) 211.

doi: http://dx.doi.org/10.1016/j.biortech.2015.04.098

7. Moriana, R., Vilaplana, F., Karlsson, S., Ribes, A., Correlation of chemical, structural and thermal properties of natural fibres for their sustainable exploitation, Carbohydrate polymers 112 (2014) 422. doi: http://dx.doi.org/10.1016/j.carbpol.2014.06.009

8. Anca-Couce, A., Obernberger, I., Application of a detailed biomass pyrolysis kinetic scheme to hardwood and softwood torrefaction, Fuel 167 (2016) 158

doi: http://dx.doi.org/10.1016/j.fuel.2015.11.062

9. Wang, S., Ru, B., Lin, H., Sun, W., Luo, Z., Pyrolysis behaviors of four lignin polymers isolated from the same pine wood, Bioresource Technology 182 (2015) 120. doi: http://dx.doi.org/10.1016/j.biortech.2015.01.127

10. Jiang, G., Nowakowski, D. J., Bridgwater, A. V., A systematic study of the kinetics of lignin pyrolysis, Thermochimica Acta 498 (2010) 61.

doi: http://dx.doi.org/10.1016/j.tca.2009.10.003
11. Miller, R. S., Bellan, J., A generalized biomass pyrolysis model based on superimposed cellulose, hemicellulose and lignin kinetics, Combustion Science and Technology 126 (1997) 97.

doi: http://dx.doi.org/10.1080/00102209708935670

12. White, J. E., Catallo, W. J., Legendre, B. L., Biomass pyrolysis kinetics: a comparative critical review with relevant agricultural residue case studies, Journal of Analytical and Applied Pyrolysi 91 (2011)1. doi: http://dx.doi.org/10.1016/j.jaap.2011.01.004

13. Brewer, C. E., Schmidt-Rohr, K., Satrio, J. A., Brown, R. C., Charactization of biochar from fast pyrolysis and gasification systems, Environmental Progress and Sustainable Energy 28 (2009) 386. doi: http://dx.doi.org/10.1002/ep.10378

14. Melkior, T., Jacob, S., Gerbaud, G., Hediger, S., Le Pape, L., Bonnefois, L., Bardet, M., NMR analysis of the transformation of wood constituents by torrefaction, Fuel 92 (2012) 271. doi: http://dx.doi.org/10.1002/ep.10378

15. Hrablay, I., Jelemenský, L., Kinetics of thermal degradation of wood biomass, Chemical Papers 68 (2012) 1725. doi: http://dx.doi.org/10.2478/s11696-014-0622-y

16. Zheng, A., Zhao, Z., Chang, S., Huang, Z., Wang, X., He, F., $\mathrm{Li}, \mathrm{H}$., Effect of torrefaction on structure and fast pyrolysis behavior of corncobs, Bioresource Technology 128 (2013) 370 .

doi: http://dx.doi.org/10.1016/j.biortech.2012.10.067

17. Hosoya, T., Kawamoto, H., Saka, S., Different pyrolytic pathways of levoglucosan in vapor- and liquid/solid-phases, Journal of Analytical and Applied Pyrolysis 83 (2008) 64. doi: http://dx.doi.org/10.1016/j.jaap.2008.06.008

18. Geng, Z., Zhang, M., Yu, Y., Theoretical investigation on pyrolysis mechanism of glycerol, Fuel 93 (2011) 92. doi: http://dx.doi.org/10.1016/j.fuel.2011.08.021

19. Paine III, J. B., Pithawalla, Y. B., Naworal, J. D., Thomas C. E. Jr., Carbohydrate pyrolysis mechanisms from isotopic labelling Part 1: The pyrolysis of glycerin: Discovery of competing fragmentation mechanisms affording acetaldehyde and formaldehyde and the implications for carbohydrate pyrolysis, Journal of Analytical and Applied Pyrolysis 80 (2007) 297. doi: http://dx.doi.org/10.1016/j.jaap.2007.03.007

20. Wu, S., Shen, D., Hu, J., Xiao, R., Zhang, H., TG-FTIR and Py-GC-MS analysis of a model compound of cellulose glyceraldehyde, Journal of Analytical and Applied Pyrolysis 101 (2013) 79. doi: http://dx.doi.org/10.1016/j.jaap.2013.02.009

21. Wang, S., Guo, X., Liang, T., Zhou, Y., Luo, Z., Mechanism research on cellulose pyrolysis by $\mathrm{Py}-\mathrm{GC} / \mathrm{MS}$ and subsequent density functional theory studies, Bioresource Technology 104 (2012) 722.

doi: http://dx.doi.org/10.1016/j.biortech.2011.10.078

22. Broido, A., Nelson, M. A., Char yield on pyrolysis of cellulose, Combustion and Flame 24 (1975) 263. doi: http://dx.doi.org/10.1016/0010-2180(75)90156-X

23. Arisz, P. W, Boon, J. J., Pyrolysis mechanisms of O-(2-hydroxyethyl) celluloses, Journal of Analytical and Applied Pyrolysis 25 (1993) 371. doi: http://dx.doi.org/10.1016/0165-2370(93)80056-6

24. Arisz, P. W., Eijkel, G. B., Boon, J. J., Linking of pyrolysis-chemical ionisation mass spectrometric and monomer compositional data of O-(2-hydroxyethyl) celluloses by canonical correlation analysis, Journal of Analytical and Applied Pyrolysis 33 (1995) 21. doi: http://dx.doi.org/10.1016/0165-2370(94)00866-Y 
25. Lomax, J. A., Commandeur, J. M., Arisz, P. W., Boon, J. J., Characterisation of oligomers and sugar ring-cleavage products in the pyrolysate of cellulose, Journal of Analytical and Applied Pyrolysis 19 (1991) 65. doi: http://dx.doi.org/10.1016/0165-2370(91)80035-7

26. Mamleev, V., Bourbigot, S., Yvon, J., Kinetic analysis of the thermal decomposition of cellulose: The change of the rate limitation, Journal of Analytical and Applied Pyrolysis 80 (2007) 141.

doi: http://dx.doi.org/10.1016/j.jaap.2007.01.012

27. Koufopanos, C. A., Maschio, G., Lucchesi, A., Kinetic modelling of the pyrolysis of biomass and biomass components, The Canadian Journal of Chemical Engineering 67 (1989) 75 .

doi: http://dx.doi.org/10.1002/cjce.5450670111

28. Várhegyi, G., Jakab, E., Antal, M. J. Jr., Is the Broido-shafizadeh model for cellulose pyrolysis true?, Energy and Fuels 8 (1994) 1345 doi: http://dx.doi.org/10.1021/ef00048a025

29. Shafizadeh, F., Chin, P. S., Thermal deterioration of wood, Wood Technology Chemical Aspects ACS Symposium Series 43 (1977) 57. doi: http://dx.doi.org/10.1021/bk-1977-0043.ch005

30. Thurner, F., Mann, U., Kinetic investigation of wood pyrolysis, Industrial and Engineering Chemistry Process Design and Development 20 (1981) 482. doi: http://dx.doi.org/10.1021/i200014a015

31. Hoekstra, E., Van Swaaij, Wim, P. M., Kersten, Sascha, R. A., Hogendoorn, Kees, J. A., Fast pyrolysis in a novel wiremesh reactor: Decomposition of pine wood and model compounds, Chemical Engineering Journal 187 (2012) 172. doi: http://dx.doi.org/10.1016/j.cej.2012.01.118

32. Liu, Q., Wang, S., Wang, K., Guo, X., Luo, Z., Cen, K., Mechanism of formation and consequent evolution of active cellulose during cellulose pyrolysis, Acta Physico-Chimica Sinica 24(11) (2008) 1957.

33. Bardet, M., Emsley, L., Vincendon, M., Two-dimensional spin-exchange solid-state NMR studies of ${ }^{13} \mathrm{C}$-enriched wood, Solid State Nuclear Magnetic Resonance 8 (1997) 25 . doi: http://dx.doi.org/10.1016/S0926-2040(96)01273-8

34. Gil, A. M., Neto, C. P., Solid-state NMR studies of wood and other lignocellulosic materials, Annual reports on NMR spectroscopy 37 (1999) 75. doi: http://dx.doi.org/10.1016/S0066-4103(08)60014-9

35. Mannu, S. L., NMR studies of wood and wood products, Progress in Nuclear Magnetic Resonance Spectroscopy 40 (2002) 151. doi: http://dx.doi.org/10.1016/S0079-6565(01)00041-3

36. Liu, Q., Wang, S., Zheng, Y., Luo, Z., Cen, K., Mechanism study of wood lignin pyrolysis by using TG-FTIR analysis, Journal of Analytical and Applied Pyrolysis 82 (2008) 170. doi: http://dx.doi.org/10.1016/j.jaap.2008.03.007

37. Miyanami, K., Fan, L. S., Fan, L. T., Walawender, W. P., A mathematical model for pyrolysis of solid particle-effects of the heat of reaction, The Canadian Journal of Chemical Engineering 55 (1977) 317. doi: http://dx.doi.org/10.1002/cjce.5450550314

38. Wichman, I. S., Atreya, A., A simplified model for the pyrolysis of charring materials, Combustion and Flame 68 (1987) 231. doi: http://dx.doi.org/10.1016/0010-2180(87)90002-2
39. Banyasz, J. L., Li, S., Lyons-Hart, J., Shafer, K. H., Cellulose pyrolysis: the kinetics of hydroxyacetaldehyde evolution, Journal of Analytical and Applied Pyrolysis 57 (2001a) 223 . doi: http://dx.doi.org/10.1016/S0165-2370(00)00135-2

40. Banyasz, J. L., Li, S., Lyons-Hart, J., Shafer, K. H., Gas evolution and the mechanism of cellulose pyrolysis, Fuel 80 (2001b) 1757. doi: http://dx.doi.org/10.1016/S0016-2361(01)00060-6

41. Font, R., Martín-Gullón, I., Esperanza, M., Fullana, A., Kinetic law for solids decomposition. Application to thermal degradation of heterogeneous materials, Journal of Analytical and Applied Pyrolysis 58-59 (2001) 703. doi: http://dx.doi.org/10.1016/S0165-2370(00)00142-X

42. Aracil, I., Font, R., Conesa, J. A., Fullana, A., TG-MS analysis of the thermo-oxidative decomposition of polychloroprene, Journal of Analytical and Applied Pyrolysis 79 (2007) 327.

doi: http://dx.doi.org/10.1016/j.jaap.2006.12.027

43. Gao, N., Li, A., Quan, C., Du, L., Duan, Y., TG-FTIR and Py-GCV/MS analysis on pyrolysis and combustion of pine sawdust, Journal of Analytical and Applied Pyrolysis 100 (2013) 26 doi: http://dx.doi.org/10.1016/j.jaap.2012.11.009

44. Ferdous, D., Dalai, A. K., Bej, S. K., Thring, R. W., Bakhshi, $N$. N., Production of hydrogen and medium Btu gas via pyrolysis of lignins in a fix-bed reactor, Fuel Processing Technology 70 (2001) 9. doi: http://dx.doi.org/10.1016/S0378-3820(00)00147-8

45. Wang, S., Ru, B., Lin, H., Sun W., Pyrolysis behaviors of four O-acetyl-preserved hemicellulose isolated from hardwoods and softwoods, Fuel 150 (2015) 243. doi: http://dx.doi.org/10.1016/j.fuel.2015.02.045

46. Gu, X., Ma, X., Li, L., Liu, Ch., Cheng, K., Li, Z., pyrolysis of polar wood sawdust by TG-FTIR and Py-GC/MS, Journal of Analytical and Applied Pyrolysis 102 (2013) 16. doi: http://dx.doi.org/10.1016/j.jaap.2013.04.009

47. Diebold, J. P., A unified global model for the pyrolysis of cellulose, Biomass and Bioenergy 7 (1994) 75. doi: http://dx.doi.org/10.1016/0961-9534(94)00039-V

48. Güllü, D., Demirbaş, A., Biomass to methanol via pyrolysis process, Energy Conversion and Management 42 (2001) 1349. doi: http://dx.doi.org/10.1016/S0196-8904(00)00126-6

49. Richards, G. N., Glycolaldehyde from pyrolysis of cellulose, Journal of Analytical and Applied Pyrolysis 10 (1987) 251 . doi: http://dx.doi.org/10.1016/0165-2370(87)80006-2

50. Anca-Couce, A., Berger, A., Zobel, N., How to determine consistent biomass pyrolysis kinetics in parallel reaction scheme, Fuel 123 (2014) 230. doi: http://dx.doi.org/10.1016/j.fuel.2014.01.014

51. Volker, S., Rieckmann, T., Progress in Thermochemical Biomass Conversion Bridgwater, A. V. (Ed.) Blackwell Science (2001) 1076. ISBN: 0-632-05533-2

52. Di Blasi, C., Modeling chemical and physical processes of wood and biomass pyrolysis, Progress in Energy and Combustion Science 34 (2008) 47. doi: http://dx.doi.org/10.1016/j.pecs.2006.12.001 